20 BMA press release archive. BMA briefing paper - presumed consent for organ donation. Available online at http://web2.bma.org.uk/ pressrel.nsf/wall/1A67C9FAF07E171D80257501003CE71D?OpenD ocument [Accessed 13 June 2014].

21 Boseley S. Taskforce opposes 'presumed consent' for organ donors. 18 November 2008. Available online at www.theguardian. com/society/2008/nov/18/organ-donation-health1 [Accessed 13 June 2008].
22 The Royal College of Surgeons. Policy position regarding organ donation. February 2013. Available online at www.rcseng.ac.uk/ policy/documents/organdonationpolicypositionFeb13.pdf [Accessed 23 May 2014].

Address for correspondence: Prof J Fabre, Kings College London, The Strand, London WC2R 2LS, UK.

Email: john.fabre@kcl.ac.uk

\title{
DNACPR decisions: challenging and changing practice in the wake of the Tracey judgment
}

\author{
Authors: Zoë Fritz, ${ }^{\mathrm{A}}$ Nick Cork, ${ }^{\mathrm{B}}$ Alex Dodd ${ }^{\mathrm{C}}$ and Alexandra Malyon ${ }^{\mathrm{D}}$
}

The Court of Appeal judgment that Janet Tracey's human rights had been breached when a 'do not attempt cardiopulmonary resuscitation' (DNACPR) form was written about her without her knowledge has far-reaching implications for clinical practice. The 'duty to consult' extends to all patients apart from those in whom it is likely that discussion would cause 'physical or psychological harm'. The ethical basis for this judgment is strong: if a patient is unaware that a resuscitation decision has been made, he or she cannot ask questions, plan the future or ask for second opinions. Clinicians have, however, expressed concerns about the logistic implications of this judgment in terms of time and resource allocation, and the possibility that doctors will refrain from making resuscitation decisions at all, rather than risk uncomfortable discussions or litigation. Problems with DNACPR decisions predate the Tracey case, and a coordinated alternative approach is needed: patients should be given information so that they can anticipate, initiate and participate in discussions; resuscitation decisions should be considered early in treatment, in a community setting or at predictable junctures; resuscitation should not be considered in isolation but within the context of other goals of care. Models addressing these issues have been developed.

KEYWORDS: Tracey judgment, DNACPR, cardiopulmonary resuscitation, resuscitation orders, medical ethics and law, European Convention on Human Rights

Authors: ${ }^{A}$ wellcome fellow in bioethics, Warwick University, Warwick, UK and consultant in acute medicine, Cambridge University Hospitals NHS Foundation Trust, Cambridge, UK; ${ }^{B}$ medical student, University of Cambridge School of Clinical Medicine, Cambridge, UK; ' medical student, University of Cambridge School of Clinical Medicine, Cambridge, UK; ${ }^{\text {nurse }}$ researcher, Department of Acute Medicine, Cambridge University Hospitals NHS Foundation Trust, Cambridge, UK.
The judgment in $R$ (on the application of Tracey) $v$ Cambridge University Hospital NHS Trust is highly significant. The Court of Appeal judged that considering a decision about a patient's cardiopulmonary resuscitation (CPR) status engages Article 8 of the European Convention of Human Rights, and that this right may be breached by a failure to involve the patient in the process leading to completion of a do not attempt cardiopulmonary resuscitation (DNACPR) form. This judgment has placed a requirement on clinicians to 'consult' with patients, except in very limited circumstances, when a DNACPR decision is considered.

While her case will be familiar to many, it is worth summarising Mrs Tracey's clinical details before looking at some of the broader questions which arise from the judgment. Janet Tracey was admitted to Addenbrooke's Hospital on 19 February 2011, after a road accident in which she sustained a serious cervical fracture. She had metastatic lung cancer and chronic lung disease with an estimated prognosis of 9 months. She was intubated and ventilated, and had two failed extubations. The family were informed that, if the third extubation failed, Mrs Tracey would be 'allowed to slip away', but there was no documentation of a discussion with Mrs Tracey.

A DNACPR form was written, and Mrs Tracey was successfully extubated and moved to the ward. The family subsequently discovered the DNACPR form and asked that it be removed, which was done. Unfortunately, Mrs Tracey deteriorated further and, after discussions with the family (Mrs Tracey was clear at this point that she did not want to discuss resuscitation herself), a second DNACPR form was completed: Mrs Tracey died on 7 March 2011 without attempted CPR.

Mrs Tracey's family brought a case against Cambridge University Hospitals NHS Foundation Trust and the secretary of state for health. Judicial review was undertaken by the Court of Appeal on 6 and 7 May 2014 as to whether the Trust had been in breach of Mrs Tracey's human rights by not informing her of a DNACPR form that had been written while she was in intensive care, and by not having 


\section{Box 1. Tracey judgment summary points.}

A DNACPR decision potentially deprives a patient of 'life-sustaining treatment'.

$>$ There should be a presumption in favour of involving the patient; not to do so deprives the patient of the opportunity to seek a second opinion.

$>$ Not to discuss or explain a decision about CPR with the patient would be in potential breach of Article 8 of the European Convention on Human Rights (the right to private and family life), which requires that individuals be notified and consulted with respect to decisions about their care.

> If a clinician 'considers that CPR will not work' the patient cannot demand it, but this does not mean that the patient is not entitled to know that the clinical decision has been taken.

$>$ Only if discussions about CPR are likely to cause 'physical or psychological harm to the patient' may they be omitted; finding the topic 'distressing' should not be a reason to omit them.

> The court rejected the submission that there was a legal requirement for a national resuscitation policy.

The full judgment can be accessed at: www.judiciary.gov.uk/wp-content/uploads/2014/06/tracey-approved.pdf

DNACPR $=$ do not attempt cardiopulmonary resuscitation

an adequately accessible DNACPR policy, and whether the secretary of state for health had been in breach of Mrs Tracey's human rights by failing to promulgate a national policy on DNACPR decisions. Box 1 lists summary points from the Tracey judgment, and Box 2 provides information about DNACPR orders more generally.

The judgment garnered considerable media ${ }^{6}$ and professional attention (http://britishgeriatricssociety. wordpress.com/2014/07/21/dysons-law-and-the-medicalregistrar-a-frontline-view and https://www.dropbox.com/s/ ptm8wtyiazgm40t/The\%20DNACPR\%20Sketch.doc along with thread from 29 June @ doctorcaldwell). ${ }^{7}$ In general, responses were polarised. The media lauded the judgment as stopping patriarchal doctors placing DNACPR 'notices' in medical records without patient knowledge. ${ }^{6}$ The medical blogosphere was dominated by concerns that clinical care would grind to a halt if every decision about every treatment with every patient had to be discussed (see blog details above), and an equally significant fear that doctors would avoid making resuscitation decisions for fear of litigation. ${ }^{7}$ If this were to happen, patients could end up receiving CPR inappropriately, which could also be in breach of their human rights. In this paper we examine these responses, as well as some of the other implications of the judgment for current clinical practice.

\section{Questions answered, questions raised...}

The 'duty to consult'. Is there now a requirement to discuss all DNACPR decisions with patients?

Paragraph 53 of the judgment stated that, as a DNACPR order was a decision that would 'potentially deprive [a] patient of life-saving treatment, there should be a presumption in favour of patient involvement', except in circumstances where a discussion might cause 'physical or psychological harm' [paragraph 54]. However, it was added that clinicians should be wary of excluding patients simply because a discussion may cause 'distress'; it was likely that many patients would find a discussion about CPR distressing. The delineation between what causes 'distress' versus distress leading to 'psychological harm' was not defined; the judges acknowledged that these are 'sensitive decisions' often made in 'very stressful circumstances', and that the court should be 'very slow' to find that decisions to exclude patients from the process, 'if conscientiously taken', violated a patient's rights. If clinicians believe that a discussion would cause harm to a patient then it appears that they should not fear finding themselves before the courts. They should, however, ensure that they clearly document their justification for this decision, as the Resuscitation Council advises in its response to the judgment. ${ }^{7}$ Although the judgment specifically did not concern decision making for incapacitated

\section{Box 2. Cardiopulmonary resuscitation and DNACPR forms: clinical and legal background.}

> The default position for a patient is that they are 'for attempted CPR'.

$>$ Of those in whom CPR is attempted, the success rate (return of spontaneous circulation) is around $18 \%{ }^{1}$ but in line with medical dramas, the general public's perception is that it is closer to $50 \%{ }^{2}$

> Success at restarting the heart is almost always followed by a significant period in intensive care and is often associated with significantly reduced mental and physical function. ${ }^{3}$

> Most patients who die in hospital do so without CPR being attempted because they have a DNACPR form in place. ${ }^{4}$

$>$ A DNACPR decision may be made at a patient's request but it is usually instigated by the clinicians looking after the patient.

> Currently the majority of DNACPR forms in the UK are instigated in hospital. Prior to the Tracey judgement, studies suggest that only about $40-50 \%$ of DNACPR forms in the UK were documented as having been 'discussed' with the patient or their relatives. ${ }^{5}$ 
patients, the Mental Capacity Act 2005 requires that patients be involved as far as possible, and that decisions made in the best interests of patients be discussed with those who might know their values, wishes and preferences.

DNACPR decisions can also be made in an emergency situation: doctors clearly should not attempt to inflict $\mathrm{CPR}$ on a patient with terminal disease just because a CPR decision had not been considered or discussed. Clinicians should, however, be proactive in having CPR discussions in anticipation of possible arrests, and resist the urge to leave considering such eventualities until an emergency occurs. The National Confidential Enquiry into Patient Outcome and Death (NCEPOD) report, Time to intervene?, ${ }^{8}$ suggested that resuscitation decisions should be explicitly recorded routinely on all acute admissions. If CPR discussions became routine (and perhaps initiated in the community), the risks of attempting unwanted CPR would also be diminished: it is equally important to ensure that patients have the opportunity both to refuse CPR and to question a clinical decision.

The Resuscitation Council (UK), British Medical Association and Royal College of Nursing were in the process of reviewing and updating their guidance, but delayed publication until after the Tracey judgment. The guidance ${ }^{9}$ makes a distinction between a decision that CPR wouldn't work in a patient who is dying, and a decision where the risks and benefits need to be carefully weighed up and discussed. It also emphasises the presumption in favour of patient involvement, reflecting the judgment.

If Article 8 is engaged by a DNACPR decision then what is the implication for the discussion of other treatments?

One of the questions raised in the courtroom was what distinguished a decision not to provide CPR from one not to provide other medical treatments. Is there now a requirement to discuss all these decisions? Several differences were alluded to. First, the judgment states: 'DNACPR decisions should be distinguished from other decisions to withhold life-saving treatment because they are taken in advance and therefore they present an opportunity for discussion with patients and their family members' [paragraph 42].

This allows clinicians making critical decisions for those who are acutely ill to do so in the patient's best interests, in the absence of a decision having previously been discussed. It also implies that there is an obligation for doctors to discuss other 'potentially life-saving' interventions with patients before they are needed. The 'physician order for life-sustaining treatment' (POLST) ${ }^{10}$ is now widely used in the USA: it encourages physicians and patients to discuss which treatments (including CPR) would be desired should the patient deteriorate. Although we work in a different paradigm in the UK, the benefits of an early conversation with a familiar healthcare professional should be self evident.

Further emphasis on the life-saving nature of CPR is made in paragraph 53 of the judgment: 'since a DNACPR decision is one which will potentially deprive the patient of life-saving treatment, there should be a presumption in favour of patient involvement.' One interpretation of this judgment is that the ruling may extend to other life-saving treatments about which decisions can be made in advance (and particularly those that might be associated with how one passes 'the closing days and moments of one's life') including, for example, admission to intensive care, or the initiation of dialysis. It does not, however, necessarily apply to those treatments that are less directly 'life saving': the hip replacement, for example. This may seem an easy distinction to make, except that most treatments can be potentially 'life saving': the patient who is immobile from his painful (not replaced) hip might die of a pulmonary embolus. It will be interesting to see the outcome if cases are brought forward questioning whether individuals' human rights have been breached on less acute matters.

\section{What effect will more discussions have on the doctor- patient relationship?}

There are concerns that a requirement to discuss DNACPR with more patients will not only distress patients but also undermine their trust in those who are providing their care. However, what the Tracey case illustrates is how much distress and distrust can be caused when patients (or those close to them) are not consulted about (or don't understand the reasons for) a DNACPR decision. If patients are not given information this may heighten their feelings of anxiety and uncertainty. ${ }^{11}$ Most patients want information about their treatment and wish to be involved in decisions about their care, ${ }^{12}$ including decisions about CPR. ${ }^{13}$ There is a strong ethical argument that a change in practice towards ensuring that patients are informed of decisions being made about them is a change in the right direction: it increases patient autonomy and potentially improves justice, because patients will have the chance to ensure that they are given the same opportunities as others.

A stronger ethical foundation for the doctor-patient interaction is likely to result ultimately in a stronger relationship, once doctors have adapted to the new culture. The media reaction was based on public shock that resuscitation decisions could be made without patients' knowledge; it was a common practice that had been unquestioned for too long. Only 40 years ago it was commonplace for doctors to defend lying to patients about their terminal diseases: ${ }^{14}$ they did so to protect their patients from distress, and to maintain optimism in the hope that it would provide a therapeutic advantage. The change in practice to openness about prognosis has strengthened the relationship; it is likely that openness about end-of-life decisions will ultimately have the same effect. Another concern is that the DNACPR decision transforms the doctor from 'care provider' to 'care withholder'. One way of overcoming this is to ensure that CPR decisions are always contextualised within a broader plan of what treatments are to be given, rather than focusing on the one to be withheld.

\section{How important is the offer of a second opinion?}

The judgment stated [paragraph 55] that, even where clinicians believed that CPR would be futile, there was still a requirement to explain to the patient that a decision had been made. If a clinician believes that a treatment will not be successful he or she is not obliged to provide it (this was established in Burke v the General Medical Council 2005 and Aintree University NHS Trust $v$ James 2013 (Box 3).

However, patients have a right to know that such a significant decision has been made, and the judgment emphasised that not telling them about the DNACPR decision deprived them of the possibility of obtaining a second opinion. In the particular case of Mrs Tracey, it was accepted that a multidisciplinary team of doctors were unanimous that she would not benefit from CPR, and that a second opinion had, in effect, been given [paragraph 


\section{Box 3. Table of cases.}

Burke v the General Medical Council [2005] EWCA Civ 1003. Lord Phillips judged that patients have the right to refuse but not to demand treatments

Aintree University NHS Trust v James [2013] UKSC 67.

Lady Hale emphasised that 'A patient cannot demand a particular treatment, but health professionals must take account of a patient's wishes when making treatment decisions'. A 'best interests' decision includes looking at a patient's welfare in the widest sense

R (Tracey) v Cambridge University Hospital NHS Foundation Trust and others [2014] EWCA Civ 822.

Lord Dyson judged that doctors have a duty to consult with patients about DNACPR decisions

DNACPR $=$ do not attempt cardiopulmonary resuscitation.

65]. Many other cases are less clear cut, and doctors are particularly bad at predicting who will survive attempted CPR. ${ }^{15}$ A new scoring system ${ }^{16}$ may help give doctors some numerical data to share in terms of likelihood of both survival and long- term deficits, but this is not (yet) widely used. A second opinion should be offered when a patient disagrees with a clinician's view, and patients should be informed that this is possible. This is in line with the joint guidance: Decisions relating to cardiopulmonary resuscitation. ${ }^{9}$

\section{How can we ensure that patients are well informed?}

An adequate 'consultation' requires that patients be adequately informed about what CPR entails, and its possible outcomes (as well as why a pre-emptive decision is necessary), so that they can anticipate, initiate and participate in discussions. Although we should accept that doctors are unlikely to be able to convey all of their clinical experience and understanding of the potential outcomes of attempted CPR, we should not be defeatist about trying. Patient information leaflets, ${ }^{17}$ provision of scoring systems, ${ }^{16}$ early conversations with familiar practitioners, ${ }^{18}$ and increasing public discussion and education will all help.

The judgment also emphasised that any policy that engaged a patient's rights under Article 8 must be accessible and clear, with patients made aware of their rights in relation to involvement in decision-making [paragraph 66]. In light of this judgment all trusts should review their current policies and ensure that these are accessible to patients.

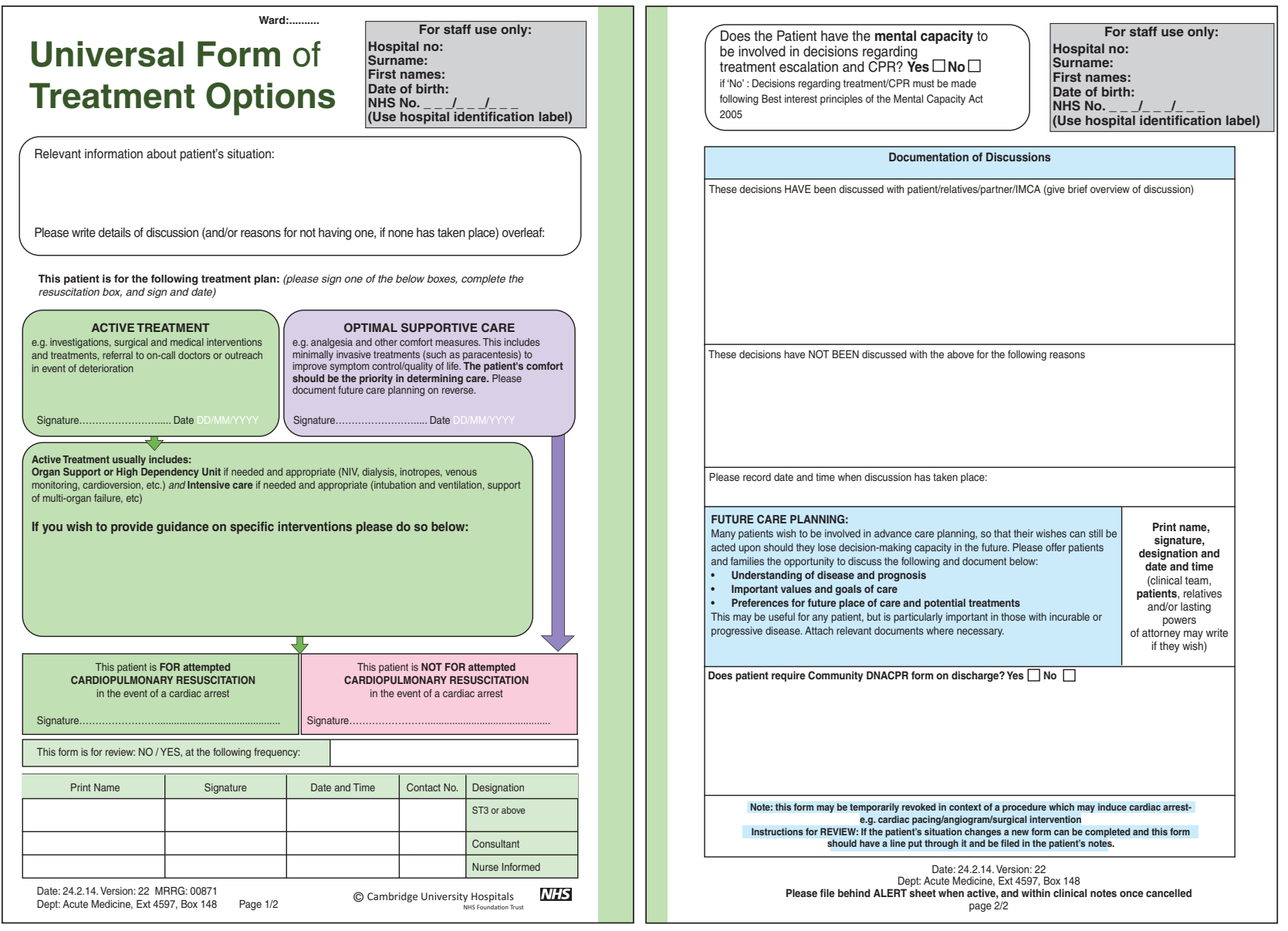

Fig 1. UFTO. This form was developed iteratively with patients, doctors and nurses to address the problems with DNACPR orders. It contextualises the resuscitation decision within overall goals of care. Reproduced with permission from Cambridge University Hospitals. DNACPR $=$ do not attempt cardiopulmonary resuscitation; UFTO = universal form of treatment options. 
Are there models available for facilitating discussions about CPR and other treatment decisions?

Lord Justice Ryder referred to Cambridge University Hospitals' new approach in his judgment in paragraph 97:

The Trust published [a new approach] on 29 April 2014 entitled the 'Universal Form of Treatment Options (UFTO) Guidelines' which recognised a distinction between active [treatment and optimal supportive care] informed by the patient's wishes. There is now an accessible policy which helpfully describes the patient's right to be consulted before a DNACPR decision is made.

This approach was not developed in response to the Tracey case, but preceded it, in recognition of the problems with DNACPR processes that have existed for some time. ${ }^{5,19}$ The Universal Form of Treatment Options (UFTO; Fig 1; see www. ufto.org) contextualises the resuscitation decision among other treatment decisions, so that the conversation can focus on treatments to be had rather than the ones to be withheld, thereby protecting the therapeutic relationship. It steers clear of tick boxes, instead using open text boxes to encourage less reflexive decision-making. It is completed for all inpatients, so that consulting about the resuscitation decision can become more routine; there is also less danger of a decision not to resuscitate being conflated with the anticipation of imminent death. The UFTO and its accompanying information sheet Talking with your doctor was evaluated in a mixed methods, before-and-after study with contemporaneous case controls ${ }^{5}$ and was found to be associated with a significant reduction $(\mathrm{p}<0.001)$ in harm events (as measured by the global trigger tool) in those patients in whom a decision not to attempt resuscitation had been made.

Accompanying qualitative work helped provide insight into the reason for this observed reduction: clinicians reported that the UFTO helped provide clarity for goals of care and reduced negative associations with resuscitation decisions. Although clinicians were initially concerned that routine consideration of resuscitation and other treatment decisions would be time consuming, they reported that this up-front work was balanced by time saved in handover and looking after deteriorating patients out of hours: the UFTO provided guidance on which treatments were desired, and could be found rapidly at the front of the notes. Although the UFTO is unique in both its universality and its flow, other alternatives have been developed in response to the problems with DNACPR forms. ${ }^{20}$ The 'treatment escalation plan' in Devon, ${ }^{21}$ the Royal United Hospital Bath form Resuscitation decision and ceiling of treatment ${ }^{22}$ and the Deciding right campaign ${ }^{23}$ all share the goal of ensuring that resuscitation decisions are not considered in isolation.

\section{Conclusion}

The Tracey judgment has questioned a long-held premise - that doctors do not need to consult with patients about withholding potentially life-saving treatments - and shaken up clinical practice, further diminishing the autonomy of doctors. The risk of clinicians evading the 'duty to consult' by avoiding consideration of CPR altogether is potentially negligent and the incidence of futile resuscitation attempts will need to be monitored carefully.
To have discussions about CPR that are both routine and meaningful is challenging. They can be made routine by having them at predictable junctures (perhaps in the community and ideally with known practitioners) and increasing patients' education about the need for such discussions. These same interventions may also render discussions more meaningful. In addition we maintain that resuscitation should always be discussed alongside overall goals of care, with emphasis on treatments to be given rather than on those to be withheld. Doing so may ease anxiety in both patients and practitioners. This change in the law has arisen from a patient whose family were concerned about the placement of the DNACPR. The beneficiaries may, however, also be those patients who do not wish to have life-saving treatments attempted but have never been given an explicit opportunity to say so, and the doctors who can confidently deliver appropriate and desired care to their patients.

\section{Acknowledgements}

We would like to thank Dr David Pitcher, Chairman of the Resuscitation Council (UK), for reading and critically editing and commenting on the paper. We would also like to thank Jonathan Fuld and Rebekah Ley for their contributions to, and reading of, the paper. Zoë Fritz is grateful to the Wellcome Trust for her funding from the Society and Ethics stream.

\section{Conflicts of interest}

Zoë Fritz and Alexandra Malyon work at Cambridge University Hospitals NHS Foundation Trust, but were not involved in the care of Janet Tracey. Zoë Fritz, along with Jonathan Fuld and other colleagues, developed UFTO. Alexandra Malyon was involved in the evaluation of the UFTO.

\section{References}

1 Nolan JP, Soar J, Smith GB et al. Incidence and outcome of inhospital cardiac arrest in the United Kingdom National Cardiac Arrest Audit. Resuscitation 2014;85:987-92.

2 Van den Bulck, Jan JM. The impact of television fiction on public expectations of survival following in hospital cardiopulmonary resuscitation by medical professionals. Eur J Emerg Med 2002;9:325-9.

3 Nolan JP, Neumar RW, Adrie C et al. Post-cardiac arrest syndrome: Epidemiology, pathophysiology, treatment, and prognostication. Resuscitation 2008;79:350-79.

4 Aune S, Herlitz J, Bang A. Characteristics of patients who die in hospital with no attempt at resuscitation. Resuscitation 2005;65:291-9.

5 Fritz Z, Malyon A, Frankau JM et al. The Universal Form of Treatment Options (UFTO) as an alternative to Do Not Attempt Cardiopulmonary Resuscitation (DNACPR) orders: a mixed methods evaluation of the effects on clinical practice and patient care. PLoS One 2013;8:e70977.

6 Eccles L. Hospital was wrong to place 'do-not-resuscitate' order on terminally ill 63-year-old as court rules doctors have duty to consult with patients first. Available online at www.dailymail.co.uk/health/ article-2660098/Hospital-wrong-place-not-resuscitate-noticeterminally-ill-63-year-old-court-rules-doctors-duty-consult-patientsfirst.html [Accessed 2 October 2014].

7 Resuscitation Council UK. Preliminary statement in response to judgment in $R$ (Tracey) $v$ Cambridge University Hospitals NHS Foundation Trust and Secretary of State for Health. Available online at https://www.resus.org.uk/pages/Statements/Statement_Tracey_ judgement.pdf [Accessed 2 October 2014]. 
8 National Confidential Enquiry into Patient Outcome and Death. Time to Intervene? A review of patients who underwent cardiopulmonary resuscitation as a result of an in-hospital cardiopulmonary arrest. London: NCEPOD, 2012. Available online at www.ncepod.org.uk/2012report1/ downloads/CAP_fullreport.pdf [Accessed 2 October 2014].

9 British Medical Association, Resuscitation Council (UK) and Royal College of Nursing. Decisions relating to Cardiopulmonary Resuscitation. Available online at www.resus.org.uk/pages/ DecisionsRelatingToCPR.pdf [Accessed 21 October 2014].

10 Fromme EK, Zive D, Schmidt TA, Cook JNB, Tolle SW. Association between physician orders for life-sustaining treatment for scope of treatment and in-hospital death in Oregon. J Am Geriatr Soc 2014;62:1246-51.

11 Fallowfield L, Jenkins V, Beveridge H. Truth may hurt but deceit hurts more: communication in palliative care. Palliat Med 2002;16:297-303.

12 Wilkinson C, Khanji, M, Cotter PE et al. Preferences of acutely ill patients for participation in medical decision-making. Qual Saf Health Care 2008;17:97-100.

13 Gorton AJ, Jayanthi NVG, Lepping P, Scriven MW. Patients' attitudes towards 'do not attempt resuscitation' status. J Med Ethics 2008;34:624-6.

14 Bok S. Lying: moral choice in private and public life. London: Pantheon Books, 1978.

15 Ebell MH, Bergus GR, Warbasse L, Bloomer R. The inability of physicians to predict the outcome of in-hospital resuscitation. J Gen Intern Med 1996;11:16-22.

16 Ebell MH, Jang W, Shen Y. Development and validation of the Good Outcome Following Attempted Resuscitation (GO-FAR) score to predict neurologically intact survival after in-hospital cardiopulmonary resuscitation. JAMA Intern Med 2013;1872-U24.
17 Sivakumar R, Raha R, Funaki A et al. Communicating information on cardiopulmonary resuscitation to hospitalised patients. Clin Med 2006;6:627-8.

18 Holland C, Bowker L, Myint P. Barriers to involving older people in their resuscitation decisions: the primary-secondary care mismatch highlights the potential role of general practitioners. Int J Clin Pract 2013;67:379-84.

19 Fritz Z, Fuld J. Ethical issues surrounding do not attempt resuscitation orders: decisions, discussions and deleterious effects. J Med Ethics 2010;36:593-7.

20 Clements M, Fuld J, Fritz Z. Documentation of resuscitation decision-making: A survey of practice in the United Kingdom. Resuscitation 2014;85:606-11.

21 NHS. Treatment escalation plan (TEP) and resuscitation decision record. Available online at www.devon.gov.uk/treatment_escalation_plan_v6.pdf [Accessed 2 October 2014].

22 Royal United Hospital Bath. Resuscitation decision and ceiling of treatment. Available online at www.ruh.nhs.uk/about/policies/documents/ clinical_policies/blue_clinical/Blue_737.pdf\#page=19 [Accessed 2 October 2014].

23 NHS England. Deciding right: Your life your choice. Available online at www.nescn.nhs.uk/wp-content/uploads/2014/05/DecidingRight-Strategy-doc-0414.pdf [Accessed 2 October 2014].

Address for corresponding author: Dr Z Fritz, Cambridge University Hospitals, Box 148, Cambridge University Hospitals NHS Foundation Trust, Hills Road, Cambridge CB2 OQQ, UK. Email: zoe.fritz@addenbrookes.nhs.uk 